(RAC 2020)

\title{
Research on the Optimization of Intangible Assets Dynamic Evaluation Index System in GEM
}

\author{
Linqiu $\mathrm{Gu}^{1}$ Chengyi $\mathrm{Pu}^{2, *}$
}

\author{
${ }^{1}$ Linqiu Gu. Central University of Finance and Economics, School of Insurance, Email: 1375275537@qq.com \\ 2 * Chengyi Pu. Corresponding author. Central University of Finance and Economics, School of Insurance \\ *Corresponding author. Email: pucy@cufe.edu.cn
}

\begin{abstract}
With the rapid development of market economy and economic globalization, we have entered a new era of knowledge economy. In the process of economic development focusing on innovation, enterprises based on knowledge and technology are emerging, which makes the proportion of intangible assets rising. But at present, there is not a relatively complete valuation system for intangible assets, and the traditional valuation methods have different degrees of limitations and defects. Therefore, it is necessary to make a dynamic evaluation index of intangible assets in the current mainstream development mode driven by technological innovation. In this paper, the gem data from 2012 to 2019are selected as samples to analyze the intangible assets of enterprises. Based on the correlation coefficient method and chart analysis, the evaluation indexes of market recognition, enterprise innovation ability and sustainable development ability are selected. Then, according to the principal component analysis method, the weight of specific indicators is determined. Finally, the dynamic valuation index of intangible assets is constructed to optimize the current situation Some intangible assets evaluation index system also enriches the gem evaluation system.

Keywords: Intangible assets, Valuation, Dynamic index model, Second-board Market
\end{abstract}

\section{创业板公司无形资产动态评价指标体系优化研究} 顾霖萩 ${ }^{1}$ 蒲成毅 ${ }^{2, *}$

\author{
1顾霖萩, 中央财经大学保险学院.电子邮箱: 1375275537@qq.com \\ $2 *$ 蒲成毅 (通讯作者), 中央财经大学 保险学院, \\ 通讯作者电子邮箱: pucy@cufe.edu.cn
}

\section{摘要}

随着市场经济的飞速发展以及经济的全球化，我们已然步入了知识经济的新时代。经济发展的重心不断向创 新靠拢的过程中，以知识和技术为发展基础的企业不断出现，使得无形资产所占比例日益攀升。但目前无形 资产评估并没有一个相对完整的估值体系，传统的几大估值方法都有不同程度的限制条件和缺陷。因此，做 出有关无形资产的动态评价指标，在当下以技术创新为动力的主流发展模式下，是有必要的。本文选择了创 业板 2012-2019 年的数据为样本，对企业的无形资产进行分析，基于相关系数法和图表分析选出了市场认可 度、企业创新能力、可持续发展能力几个层面的评价指标，再根据主成分分析法来确定具体指标的权重，最 终构建了无形资产动态估值指数，优化现有的无形资产评价指标体系的同时也丰富了创业板的评价体系。

关键词: 无形资产, 估值, 动态指数模型, 创业板.

\section{1. 引言}

当下，市场经济正不断发展完善，经济逐渐全 球化使得上市企业面临的生存挑战变成了如何在全 球市场的竞争中脱颖而出。随着知识经济的发展, 低 成本和差异化的竞争策略已失去了优势。新的主流 发展模式成为了创新。在创新已经成为发展关键的 时刻, 如何进一步发展知识经济的优势从而使得我 国企业更具核心竞争力，是国家和企业拥有者共同
关心的问题。而发展知识经济, 其中重要的一步就是 评价宏观整体的无形资产发展变化情况。

2009 年，我国创业板的正式上市为高新技术企 业提供了新的融资渠道，还通过对上市公司进行有 效的资产评估, 加速了我国研发支出的资本化进程 推动了知识经济得到进一步的发展，经济发展的重 心不断地向创新靠拢, 以知识和技术为重要发展基 础的企业如雨后春笋般出现，使得无形资产在企业 
资产中所占比例日益攀升, 扮演的角色也越来越重 要。但目前无形资产评估所需要面对的问题还很多: (1)像创意产业，文化传媒产业一类的文化类资产， 由于知识产权的专有性, 估值较难。(2) 受到银行认 可的无形资产质押物仅限制于商标权和专利权, 不 仅要求的门槛较高, 而且这样的抵押担保报告的质 量和权威性普遍较低。(3) 目前无形资产估值指数的 研究体系尚不完善, 普遍通用的三大方法即, 成本法、 收益法、市场法并不能模拟多个公司的无形资产整 体变化趋势。正因如此, 如何高效的评价以知识形态 存在的无形资产, 就成为了新兴企业发展必须面对 的问题; 做出有关无形资产的动态评价指标, 在当下 的主流发展模式下，也是十分有必要的。

我国在助力科创型新兴企业成长的方面已经小 有成就: 2009 年正式开市的创业板，2019 年正式开 市的科创板以及 2020 年 8 月创业板的注册制正式开 市……中国已经在这条路上摸索着前进了。由于创 业板对比科创板成熟许多, 可选择研究的数据也比 较丰富, 本文选择了创业板上市公司的 2009 年到 2019 年的数据为样本, 对创业板公司的无形资产进 行分析, 并得出了以下结论: (1) 创业板行业中, 制 造业占比超过百分之五十, 占比最大, 其次是信息传 输以及信息技术服务业, 占比达 $18.37 \%$, 两者总占 比超过四分之三。(2) 在这两个行业中, 无形资产的 主要表现形式为专利技术、企业所占的市场份额以 及专业技术人员。

因此根据以上结论, 本文基于相关系数法和图 表相关分析法选出了三个评价的方面: 市场认可度 企业创新能力、可持续发展能力, 对企业的无形资产 进行评估。再根据主成分分析法确定三个方面的具 体评价指标的权重, 最终构建了新的无形资产动态 估值指数。指数完成后, 在两个层面上全面的检验了 指标的合理性：宏观上通过拟合优度以及模型在时 间序列上的稳定型来检验; 微观上通过指标在不同 评价个体之间的横向稳定性来检验。通过全方位的 检验来确保新指数的合理性, 并使用创业板的最新 行业数据作为样本数据进行实证检验, 进一步保证 了指标的现实性, 为创业板上市公司的无形资产评 价体系提供了新思路和新方向, 也为监管部门、企业 拥有者提供了参考。

\section{2. 文献综述}

由于无形资产是随着经济的发展地位才逐渐重 要的, 所以其概念和边界目前全球还没有一个统一 的定论。在国外, 19 世纪中, 美国的经济学家托尔 斯 - 本德首次提出无形资产的概念。至此, 无形资产 逐渐被学者们列入了研究范围。在我国, 1995 年吴 贵生首先提出了资产的概念, 进而说明了无形资产 是没有实物形态的资产; 同时他还指出, 在资产评估 界, 资产评估的定义是为经济活动中资产的价值做 出的判断与评价。随后, 汤湘希 (1997) 对无形资产 的定义做出了补充: 能带来长期收益的法律或者契
约所赋予的特殊权利以及获取超额利润的特殊经济 资源 ${ }^{[1]}$ 。之后, 姜楠 (2001) 指出无形资产的价值是 其获利能力的资本化, 无形资产评估是在特定条件 下评估人员通过模拟市场对无形资产内在的且能转 化为现实的获利能力资本化的一种价值估计 ${ }^{[2]}$ 。曹洪 军 (2005) 总结了无形资产价值的体现, 提出无形资 产价值的内涵是依附于无形资产并产生相应的超额 附加值, 对其价值评估是基于无形资产自身的获利 能力以及无形资产得以发挥作用的空间和条件。庞 淄镡、张煦 (2015) 对无形资产估值的影响因素作出 总结, 他们指出无形资产评估是指以无形资产价值 形成理论为基础, 考虑影响无形资产价值变动的各 种因素, 最终选用适当的评估方法, 对企业无形资产 在一定时点上的价值进行量化的过程。无形资产评 估价值的特点有弱对应性、虚拟性、增贬值性以及价 值构成与一般商品有所差别。无形资产评估价值的 影响因素包括成本、效益、技术以及无形资产的使用 期限。

目前, 无形资产估值的无形资产评估的基本方 法主要有以下几项:

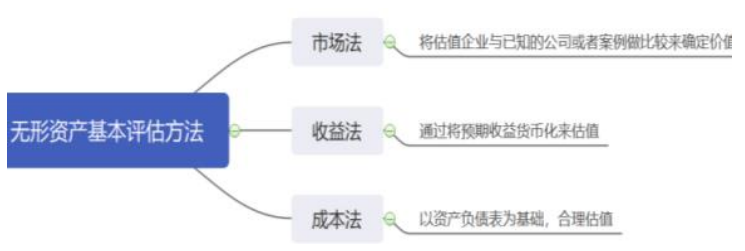

图 1 传统评估方法

随后, 有许多学者都指出评估时收益法应该作 为主要首选方法是符合无形资产特性的选择。但在 实际的应用中, 由于不同的方法受到不同条件的限 制, 这些常用的基本企业评估方法都各有鄙陃:

收益法最直观的使用条件就是需要资产的收益 可以货币化, 并且要求所评估资产的年限和风险都 可预测, 也因此决定了高风险的资产就很难使用收 益法来评估。对于成本法来说, 必须要有一定的历史 资料才能进行估值, 且要求每项资产都可被单独评 估, 导致了用成本法估值时, 需要将企业的一个完整 有机体分离来定价。而市场法必须依存于公开活跃 的市场, 并且市场上必须有类似资产, 这种通过比较 的方式得出的估值结果, 忽视了风险因素, 并且很可 能错误估计所参照的企业的价值。

除了以上的三种基本传统估值方法, 学者们也 研究出不少的新方法:

2001 年, 骆正清、陈艳辉 ${ }^{[3]}$ 提出了成本收益双 折现法, 指出无形资产的价格=历史成本折现值+使 用过程中价值积累+超额预期收益现值-损耗-贬值。 张坤 (2003) ${ }^{[4]}$ 提出评估无形资产时, 除了考虑历史 成本或者重置成本, 还需要考虑该无形资产的稀缺 性和效用的大小, 并将其命名为复合成本法。陈引、 郑明川 (2005) 认为实物期权无形资产价值可以分为 期权和资产两个价值部分, 并且两个部分可以分别 估值: 期权价值可对应期权法, 资产价值则对应使用 
普通资产评估方法。孙玉艳、张文德（2010）提出了 收益分成法, 即, 利用调查的专家意见结合层次分析 来确定收益分成率, 最后用分成率乘以评价初期的 评估值即可得到无形资产的评估值。周盟农、黄校徽 (2016) ${ }^{[5]}$ 指出: 无形资产的价值 $=$ 常规的价值 + 实物 期权价值; 其中实物期权价值体现在企业未来获得 现金流入的机会, 两种价值分别对应传统无形资产 价值估计方法和实物期权法。谢如松 (2017) ${ }^{[6]}$ 在对 传统收益法做出大量分析之后, 提出传统的收益法 测算方式评估的准确性较低, 如果引入灰色关联度 就能最大程度的去除主观的影响, 大大提高精确性。

综上可知, 尽管在对无形资产的估值方面, 学 者们已经有了一定的建树, 但是随着科技和经济不 断的发展, 上市公司无形资产的定义边界不断模糊 化, 在向外延伸的同时也不断出现新的无形资产类 型。并且, 目前针对于一些特定板块的无形资产评价 也并没有一个较为完整的体系, 因此本文从现有理 论和创业板较新的数据分析入手, 建立了一个创业 板初步的无形资产动态评价指标体系。

\section{3. 无形资产评价指数建立}

\section{1 研究范围划定}

创业板是我国专为中小企业、创业型企业以及 高科技产业企业提供融资平台的证券交易市场, 是 对主板市场的补充, 即第二股票交易市场。因此, 创 业、1 板的上市门槛相对较低, 上市主体主要是中小 型企业。这些企业的特征主要是: 企业规模小、盈利 能力较低、成长性高、成长速度快。因此, 区别于其 他板块上市公司的无形资产估值, 对于在创业板上 市的企业无形资产, 更应该长远的考虑, 从更长一些 的时间序列上对其进行分析和估值。

\section{2 确定研究对象}

无形资产，我国通用的解释是企业拥有或者可 以控制的没有实物形态的非货币性资产。在国际会 计准则以及美国会计准则的规定中, 无形资产通常 是指企业的专利权、商标权、版权、特许权、市场份 额、以及计算机软件类等 ${ }^{[7]}$ 。无形资产并没有物质实 体, 而是表现为某种技术或者法定的权利。本文研究 的无形资产来自于创业板上市公司, 数据来自 RESSET 数据库、 CSMAR 数据库。

表 12018 年 - 2019 年创业板年度相关数据

\begin{tabular}{ccccc}
\hline & $\begin{array}{c}\text { 营业总收 } \\
\text { 入增长率 } \\
(\%)\end{array}$ & $\begin{array}{c}\text { 净利润 } \\
\text { 增长率 } \\
(\%)\end{array}$ & $\begin{array}{c}\text { 净资产 } \\
\text { 收益率 } \\
(\%)\end{array}$ & $\begin{array}{c}\text { 毛利率 } \\
(\%)\end{array}$ \\
\hline 2018 & 15.85 & & 2.44 & 29.57 \\
\hline 2019 & 11.7 & 29.1 & 3.4 & 29.7 \\
\hline
\end{tabular}

\section{3 研究假设}

由于在创业板上市的公司位于我国的不同地区， 考虑到地区与地区之间的经济发展并不均衡, 企业 与企业之间获取外部资源的能力也并不统一; 此外, 不排除在选择样本数据时可能会产生偏误, 在针对 创业板无形资产编制动态评价指数之前, 我们做出 以下假设:

(1) 本文数据的根本来源是各企业对外披露的 公司年报, 因此为了避免样本在选择时出现偏差和 遗漏变量, 我们假设各企业在各地区的外部政策性 影响因素 (政府关系、相关政策等) 都相同; 并且假 设在编制无形资产评价指数时没有样本选择偏误即 避免了内生性差异。

（2）由于我们在实证检验的过程中需要将不同 的企业之间进行横向比较, 而在创业板上市的各企 业所处地区各异, 导致不同公司所处环境的资源分 布、经济实力、产业结构往往层次不齐, 因此我们假 设各地区的经济水平基本均衡, 就能排除各企业的 区位差异导致的影响, 着重反映无形资产的作用 ${ }^{[8]}$ 。

\section{4 评价指标的确定}

\section{4. 1 现状概述}

与普通主板上市的企业不同, 在创业板上市的 公司大多为高科技技术产业, 有较好的成长性。据新 出炉的 2020 年的中报显示, 创业板的行业配置如图 2 所示。

由图 2 可知, 创业板行业分布比较集中, 占据 市场绝大部分的行业为制造业，比例超过了一般; 其 次是信息技术行业，但其所占比例远小于制造业。

据深圳证券交易所发布的《深交所多层次资本 市场上市公司实证分析报告》, 本文整理了创业板近 五年来平均收入增长率平均净利润增长率等数据。 据表 1 和表 2 可知: 创业板的企业大都处于发展阶 段, 且总体来看, 净利润和总收入都在以较高的增速 增长。因此, 对于创业板公司无形资产的估值问题, 不仅需要考虑该企业当下的市场占有率, 还需要多 方面考虑其创新能力以及其在未来市场上的表现能 力和可持续能力。 


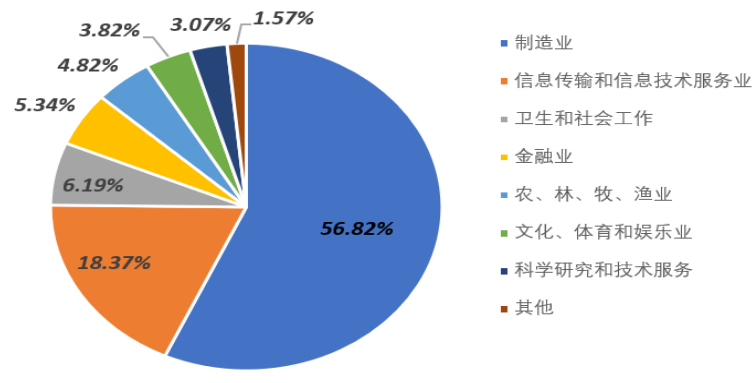

图 2 创业板行业分布

\subsection{2 评价维度、具体指标的选取}

在知识经济时代的背景下，无形资产对企业的 价值贡献度是极大的：无形资产不仅是提升企业价 值的最主要的资产，还与企业的核心竞争力有着不 可分割的关系。因此，部分无形资产的价值是通过企 业来表现出来的。因此，评价无形资产不能脱离企业。

表 22015 年 一 2017 年创业板年度相关数据

\section{平均营业收入 平均净利润 增长率 $(\%)$ 增长率}

(\%)

\begin{tabular}{llll}
\hline 2015 & 29.03 & 24.84 & 9.86 \\
\hline 2016 & 33.05 & 36.39 & 10.5 \\
\hline 2017 & 27.83 & -15.21 & 7.3 \\
\hline
\end{tabular}

为了能更加全面的评价无形资产, 本文选取了 三个时间节点, 也是三个不同维度的评价方向, 即该 企业当前的市场份额、短期内的市场表现以及长期 的企业发展潜力; 其中当前的市场份额对应于该企 业目前的市场认可度; 短期内的市场表现体现为企 业创新能力是长期的发展潜力体现为企业可持续发
表 3 评价维度表

\begin{tabular}{ccc}
\hline & 时间序列 & 评价维度 \\
\hline 1 & 目前已取得的市场份额 & 市场认可度 \\
\hline 2 & 短期的企业市场表现 & 企业创新能力 \\
\hline 3 & 长期的企业发展潜力 & 可持续发展能力
\end{tabular}

展能力。简述如表 3 :

（1）市场认可度

市场认可度是一个企业的产品和服务被消费者 所认同的程度, 是企业长时间的积累结果, 衡量一个 企业当前的市场竞争力如何, 最好的维度就是市场 认可度。而最直观的体现市场认可度的指标就是市 场占有率。市场占有率一定程度上直接反应了该企 业在市场里的竞争地位以及企业所拥有消费者的忠 诚度, 除此之外, 市场占有率还能反应出企业一定时 间内的经营业绩。因为创业板公司大都属于高新技 术产业，因此与企业的经营业绩最相关的资产当属 无形资产了。所以本文选择了市场占有率作为市场 认可度维度下的一级指标。

\section{（2）企业创新能力}

企业的创新能力, 主要是用来衡量企业在完成 与创新的相关活动和研究的能力, 所以它可以很好 的衡量一个企业在最近的一段短期的时间中，企业 将会有怎样的表现, 如果创新能力好, 那么该企业在 市场上的表现就一定不错, 进而意味着该公司的无 形资产也是更有价值。

由于企业无形资产的最主要来源就是创新产生 的知识产权, 而知识产权带来的收益就是无形资产 的价值, 因此与无形资产的价值相关的一个非常重 要的因子就是创新能力。具体体现为, 企业的研发团

表 4 指标综合表

\begin{tabular}{|c|c|c|}
\hline 评价维度 & 评价指标 & 指标的具体含义 \\
\hline 市场认可度 & 市场占有率 & 企业销售收入/行业总销售收入 \\
\hline \multirow{3}{*}{ 企业创新力 } & 技术性无形资产 & 技术性无形资产/无形资产总额 ${ }^{[7]}[5](7-12)$ \\
\hline & 研发团队投入强度 & 研发人员数/企业总员工数量 \\
\hline & R\&D 支出比重 & R\&D 支出/营业收入 \\
\hline \multirow{6}{*}{$\begin{array}{c}\text { 可持续发展 } \\
\text { 能力 }\end{array}$} & 主营业务收入增长率 & 主营业务收入增长率 $=($ 本期主营业务收入-上期主营业务收入 $) /$ 上期主营业务收入 $\times 100 \%{ }^{\left[{ }^{[8]}\right.}$ \\
\hline & 净利润增长率 & 净利润增长率 $=($ 本年净利润增长额 $\div$ 上年净利润 $) \times 100 \%$ \\
\hline & 总资产增长率 & 总资产增长率=本年总资产增长额/年初资产总额 ×100\% \\
\hline & 股东权益比率 & 股东权益比率=股东权益总额/资产总额 \\
\hline & 资本保值增值率 & 资本保值增值率=期末所有者权益％期初所有者权益 x 100\% \\
\hline & 可持续增长率 & $\begin{array}{c}\text { 可持续增长率=股东权益收益率 } \times(1-\text { 股利支付率 }) /(1-\text { 股东权益收益率 } \mathrm{x}(1-\text { 股利支付率 })) \\
=\mathrm{ROE} * \text { 自留率/ (1-ROEx 自留率 }\end{array}$ \\
\hline
\end{tabular}




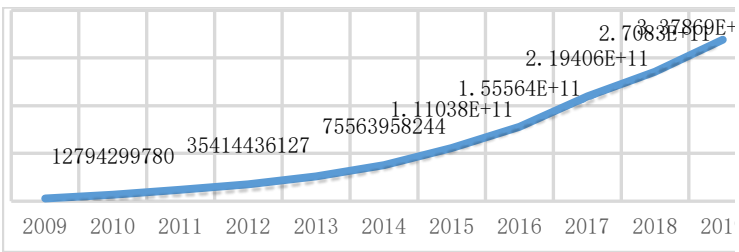

图 3 无形资产期末变化趋势图

队是否能提出新颖的想法, 并把这些想法转化为实 物。这就与该企业的研发团队以及企业对研发的投 入力度有关了。因此本文选择了研发团队投入强度、 R\&D 支出比重以及技术无形资产比重三个一级指标, 从不同角度描述了企业的创新能力。其中, 为了证明 技术型无形资产所占的比重可以影响到创业板上市 企业的无形资产价值, 本文将从 2017 年到 2019 年, 技术型无形资产与创业板上市企业无形资产随着时 间的发展趋势用折线图表示出来, 由图 1 和图 2 可 知, 两者的趋势高度相似; 并且将两者的数据作为变 量进行相关变量分析, 由图 3 可知, 两者的相关性 系数 $R^{2}>0.75$, 并且值非常接近 1 , 证明两者相关性 极强, 技术型无形资产比重能在很大程度上反映无 形资产的价值变化情况。

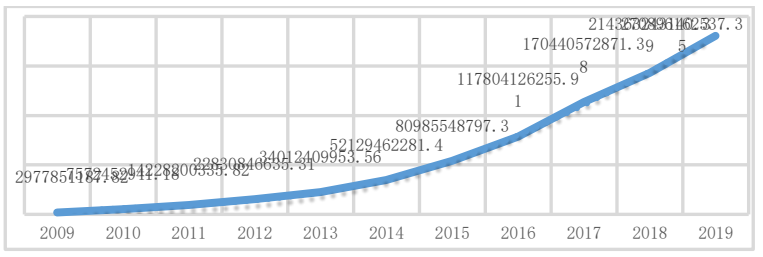

图 4 技术性无形资产变化趋势图

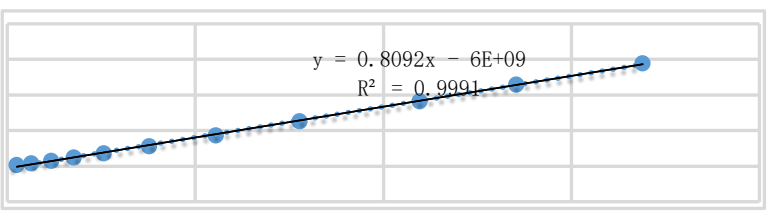

图 5 技术性无形资产与无形资产的相关性散点图

(3) 企业可持续发展能力

可持续发展能力是指企业在长期的成长和发展 的过程中, 能够维持现值不降低而且实现增长, 保持 原有优势和竞争实力 抵抗风险进而实现持续盈利、 稳健发展的能力。

为了体现企业维持现值并不断发展的能力, 本 文选取了净利润增长率、主营业务收入增长率以及 总资产增长率作为衡量的一级指标; 而风险抵御能 力则选择: 股东权益比率来体现公司抵御外部冲击 的能力; 再用资产保值增值率来表现企业未来的安 全状况与运营效益; 最后用可持续增长率来总体衡 量一下企业不改变现有条件, 其销售所能达到的增 长率。以上各个一级指标, 从不同角度衡量了企业的 可持续发展能力, 而无形资产作为企业最主要用来 发展企业和提高核心竞争力的资产形式, 其可以直 接对企业可持续发展能力的产生影响, 因此对无形
资产的估值与对企业可持续发展能力的评价息息相 关。综上, 本文对评价维度和指标列于表 4。

本文选用主成分分析法将多个指标联系起来, 利用降维的思想将上文所选择的多个指标合并转化 为几个综合指标 (即各个主成分), 并且各主成分所 反映的新信息均不重复, 并最终根据各主成分的权 重加和起来, 得到无形资产的评价指数。该方法的具 体数学模型如下:

设有 $\mathrm{n}$ 个评估对象, 每个对象有 $\mathrm{p}$ 项观察指 标: $X_{1}, X_{2}, X_{3}, \cdots \cdots, X_{P}$, 就可得到原始的数据矩 阵: $\boldsymbol{X}=\left[\begin{array}{cccc}x_{11} & x_{12} & \ldots & x_{1 p} \\ x_{21} & x_{22} & \ldots & x_{2 p} \\ \vdots & \vdots & . & \vdots \\ x_{n 1} & x_{n 2} & \ldots & x_{n p}\end{array}\right]=\left(X_{1}, X_{2}, X_{3}, \ldots \ldots, X_{P}\right)$

其中, $X_{1}=\left(x_{1 i}, x_{2 i}, \ldots, x_{n i}\right)^{\prime}, \mathrm{i}=1,2,3, \cdots, \mathrm{p}$ 在利用该矩阵 $X$ 的 $\mathrm{p}$ 个向量 $X_{1}, X_{2}, X_{3}, \cdots \cdots, X_{P}$, 通过线性的组合得到:

$\left\{\begin{array}{c}F_{1}=a_{11} X_{1}+a_{21} X_{2}+\cdots+a_{p 1} X_{p} \\ F_{2}=a_{12} X_{1}+a_{22} X_{2}+\cdots+a_{p 2} X_{p} \\ F_{3}=a_{13} X_{1}+a_{23} X_{2}+\cdots+a_{p 3} X_{p} \\ \vdots \\ F_{p}=a_{1 p} X_{1}+a_{2 p} X_{2}+\cdots+a_{p p} X_{p}\end{array}\right.$

可简 写为 $F_{i}=a_{1 i} X_{1}+a_{2 i} X_{2}+\cdots+a_{p i} X_{p}$, $\mathrm{i}=1,2,3, \cdots, \mathrm{p}$ 其中 $X_{i}$ 是 $\mathrm{n}$ 维向量, 因此 $F_{i}$ 也是 $\mathrm{n}$ 维 向量。上述的方程组需要满足, $a_{1 i}{ }^{2}+a_{2 i}{ }^{2}+\cdots+a_{p i}{ }^{2}=$ $1, \mathrm{i}=1,2,3, \ldots, \mathrm{p}$, 且所有的系数 $a_{i j}$ 都要满足下列原则:

(1) 任意两个 $F_{i}$ 和 $F_{j}$ 之间不相关

(2) $F_{1}$ 是 $X_{1}, X_{2}, X_{3}, \ldots \ldots, X_{P}$ 的一切满足上述方 程组的线性组合中方差最大的, $F_{2}$ 是与 $F_{1}$ 不相关的 $X_{1}, X_{2}, X_{3}, \ldots \ldots, X_{P}$ 一切线性组合中方差最大的, 以此 类推, $F_{p}$ 是与 $F_{1}, F_{2}, F_{3}, \ldots, F_{p}$ 都不相关的 $X_{1}, X_{2}$, $X_{3}, \ldots \ldots, X_{P}$ 一切线性组合中方差最大的。

设 $F=a_{1} X_{1}+a_{2} X_{2}+\cdots+a_{p} X_{p}=\alpha^{\prime} X$

其中 $\alpha^{\prime}=\left(a_{1}, a_{2}, \ldots, a_{p}\right)^{\prime}, X=\left(X_{1}, X_{2}, \ldots, X_{p}\right)^{\prime}$ 。此 时, 寻求主成分就是寻找到 $X$ 的线性函数使得 $\alpha^{\prime} X$ 相应的方差尽可能达到最大值, 即

$\operatorname{Var}\left(\alpha^{\prime} X\right)=E\left(\alpha^{\prime} X-E\left(\alpha^{\prime} X\right)\right)\left(\alpha^{\prime} X-E\left(\alpha^{\prime} X\right)=\alpha^{\prime} E(X-\right.$ $E(X))(X-E(X))^{\prime} \alpha=\alpha^{\prime} \Sigma \alpha$

达到最大值, 且 $\alpha^{\prime} \alpha=1$.

接下来建立协方差矩阵 $\Sigma$, 反映数据之间的密切 程度, 计算公式为: $s_{i j}=\frac{1}{n-1} \sum_{k=1}^{n}\left(x_{k-i}-x_{i}\right)\left(x_{k-j}-x_{j}\right)$, $(i, j=1,2, \cdots, p)$

则 $X_{1}, X_{2}, X_{3}, \cdots \cdots, X_{P}$ 的主成分就是以 $\Sigma$ 的特 征向量为系数的线性组合, 他们互不相关, 其方差为 $\Sigma$ 的特征根, 由于 $\Sigma$ 的特征根 $\lambda_{1} \geq \lambda_{2} \geq \cdots \geq \lambda_{p} \geq 0$, 因此有 $\operatorname{var}\left(F_{1}\right) \geq \operatorname{Var}\left(F_{2}\right) \geq \cdots \geq V_{a_{r}}\left(F_{p}\right) \geq 0$, 因此 主成分的名次是按照特征根大小的顺序排列的。 
在实际问题中时，一般不会将所有主成分全部 选取, 而是根据特征值大于 1 , 选出前 $\mathrm{k}$ 个满足要求 的主成分。并将前 $\mathrm{k}$ 个主成分的累计贡献率定义为 $\sum_{i=1}^{K} \lambda_{i} / \sum_{i=1}^{P} \lambda_{i^{\circ}}$ 而各主成分占最终结果的权重则可 用该主成分的贡献率与前 $\mathrm{k}$ 个主成分的累计贡献率 的比值来确定, 即: $\lambda_{i} / \sum_{i=1}^{\kappa} \lambda_{i}$ 。最终得出无形资产 指数的表达式。

\section{4. 实证检验}

\section{1 数据来源与说明}

本文的研究对象为创业板的上市公司, 并针对 创业板上市公司的无形资产进行了指数的趋势拟合。 本文的数据主要来自 wind 数据库、RESSET 数据库、 CSMAR 数据库, 考虑到: (1) 创业板在 2009 年 10 月 才正式开市，至今也依旧开放;（2）本文的评价指标 选择了市场占有率等受上市公司数量影响较大的指 标, 因此为了数据的可得性以及指标的稳定性, 本文 选取了 2012 年到 2019 年之间的样本数据。剔除掉 信息不完整和 ST 企业后, 有效样本为 4945 个, 其 中 12 年 390 个, 13 年 447 个, 14 年 577 个, 15 年 410 个, 16 年 730 个, 17 年 791 个, 18 年 804 个, 19 年 796 个。在确定了样本数据之后, 利用 SPSS 软 件对所有数据做标准化处理。

\section{2 无形资产指数的确定}

\section{2.1 方法检验}

在进行主成分分析法之前, 先对已经标准化的数 据进行 KMO 检验以及 Bartlett 检验, 观察本案例是 否适合用主成分分析法来计算:

表 5 KMO 和 Bartlett 检验结果表

\begin{tabular}{|c|c|c|}
\hline KMO 值 & & 0.595 \\
\hline \multirow{3}{*}{ Bartlett 球形度检验 } & 近似卡方 & 708.933 \\
\hline & $\mathrm{df}$ & 36 \\
\hline & $\mathrm{p}$ 值 & 0.000 \\
\hline
\end{tabular}

根据表 5 可知, KMO 值为 0.595 大于 0.5 , Bartlett 检验对应 $\mathrm{p}$ 值为 0.000 小于显著水平 0.05 , 表明 Bartlett 球形检验和 KMO 检验均通过, 本文选取的 数据适合进行主成分分析, 接下来的计算有效。

\subsection{2 提取主成分}

首先计算协方差矩阵: $\Sigma=\left(s_{i j}\right)_{P \times P}$, 再计算协 方差矩阵的特征根, 其中矩阵的前 $\mathrm{m}$ 个大于 1 的特 征值就是前 $\mathrm{m}$ 个主成分对应的方差, 并计算各主成 分的方差解释率 $a_{i}=\lambda_{i} / \sum_{i=1}^{m} \lambda_{i}$; 最后根据特征值 大于 1 的判断标准, 提取了四个主成分。计算所得 的方差解释率如表 6 所示。

\subsection{3 计算主成分之间的权重}

根据各指标对应的的方差解释率加权后, 新的 方差解释率即权重依次为:

主成分一: $20.826 / 64.447=32.31 \%$; 主成分二: 19. $630 / 64.447=30.46 \%$;

主成分三: $12.716 / 64.447=19.73 \%$; 主成分四: 11. $275 / 64.447=17.49 \%$;

表 6 方差解释率表格

\begin{tabular}{|c|c|c|c|c|c|c|}
\hline \multirow{2}{*}{$\begin{array}{l}\text { 编 } \\
\text { 号 }\end{array}$} & \multicolumn{3}{|c|}{ 特征根 } & \multicolumn{3}{|c|}{ 主成分提取 } \\
\hline & 特征根 & $\begin{array}{c}\text { 方差解 } \\
\text { 释率\% }\end{array}$ & 累积\% & $\begin{array}{c}\text { 特征 } \\
\text { 根 }\end{array}$ & $\begin{array}{c}\text { 方差解 } \\
\text { 释率\% }\end{array}$ & 累积 $\%$ \\
\hline 1 & 1.874 & 20.82 & 20.82 & 1.87 & 20.82 & 20.82 \\
\hline 2 & 1.767 & 19.63 & 40.45 & 1.76 & 19.63 & 40.45 \\
\hline 3 & 1. 144 & 12.71 & 53.17 & 1.14 & 12.71 & 53.17 \\
\hline 4 & 1.015 & 11.27 & 64.44 & 1.01 & 11.27 & 64.44 \\
\hline 5 & 0.899 & 9.98 & 74.43 & - & - & - \\
\hline 6 & 0.776 & 8.61 & 83.05 & - & - & - \\
\hline 7 & 0.644 & 7.15 & 90.20 & - & - & - \\
\hline 8 & 0.497 & 5.51 & 95.72 & - & - & - \\
\hline 9 & 0.385 & 4. 27 & 100 & - & - & - \\
\hline
\end{tabular}

表 7 载荷系数

\begin{tabular}{|c|c|c|c|c|c|}
\hline \multirow{2}{*}{ 名称 } & \multicolumn{4}{|c|}{ 载荷系数 } & \multirow{2}{*}{ 公共度 } \\
\hline & 成分 1 & 成分 2 & 成分 3 & 成分 4 & \\
\hline 市场占有率 & 0.21 & -0.118 & 0.429 & 0.672 & 0.694 \\
\hline $\begin{array}{c}\text { 技术性无形资 } \\
\text { 产所占比重 }\end{array}$ & -0.171 & 0.11 & 0.76 & 0.016 & 0.62 \\
\hline $\begin{array}{c}\text { 研发人员数量 } \\
\text { 占比 }\end{array}$ & -0.482 & 0.677 & 0.161 & 0.109 & 0.729 \\
\hline $\begin{array}{c}\text { 研发投入占营 } \\
\text { 业收入比例 }\end{array}$ & -0.596 & 0.625 & 0.055 & 0.042 & 0.751 \\
\hline $\begin{array}{c}\text { 主营业务收入 } \\
\text { 增长率 }\end{array}$ & 0.609 & 0.519 & 0.12 & -0.215 & 0.701 \\
\hline 净利润增长率 & 0.588 & 0.507 & 0.055 & -0.2 & 0.645 \\
\hline 股东权益比率 & -0.424 & 0.345 & -0.381 & -0.034 & 0.446 \\
\hline $\begin{array}{c}\text { 资本保值增值 } \\
\text { 率 }\end{array}$ & 0.118 & 0.188 & -0.419 & 0.657 & 0.657 \\
\hline 可持续增长率 & 0.551 & 0.459 & -0.122 & 0.172 & 0.559 \\
\hline 市场占有率 & 0.21 & -0.118 & 0.429 & 0.672 & 0.694 \\
\hline $\begin{array}{c}\text { 技术无形资产 } \\
\text { 占比 }\end{array}$ & -0.171 & 0.11 & 0.76 & 0.016 & 0.62 \\
\hline $\begin{array}{c}\text { 研发人员数量 } \\
\text { 占比 }\end{array}$ & -0.482 & 0.677 & 0.161 & 0.109 & 0.729 \\
\hline $\begin{array}{c}\text { 研发投入占营 } \\
\text { 业收入比例 }\end{array}$ & -0.596 & 0.625 & 0.055 & 0.042 & 0.751 \\
\hline $\begin{array}{c}\text { 主营业务收入 } \\
\text { 增长率 }\end{array}$ & 0.609 & 0.519 & 0.12 & -0.215 & 0.701 \\
\hline 净利润增长率 & 0.588 & 0.507 & 0.055 & -0.2 & 0.645 \\
\hline 股东权益比率 & -0.424 & 0.345 & -0.381 & -0.034 & 0.446 \\
\hline $\begin{array}{c}\text { 资本保值增值 } \\
\text { 率 }\end{array}$ & 0.118 & 0.188 & -0.419 & 0.657 & 0.657 \\
\hline 可持续增长率 & 0.551 & 0.459 & -0.122 & 0.172 & 0.559 \\
\hline
\end{tabular}




\subsection{4 计算主成分载荷系数值}

载荷值是反映主成分与原变量 (本文中即各个 指标)之间的相互关联程度的变量, 计算公式为: $l_{i j}=\sqrt{\lambda_{i}} a_{i j}$, 下面通过载荷系数值表格分析展示 主成分对于九个指标的信息提取情况, 以及上文 提取出的四个主成分和各指标之间的对应关系:

因为载荷系数绝对值大于 0.4 时即说明该项和 主成分有对应关系，从表 7 可知: 所有指标所应的 共同度值均高于 0.4 , 意味着各指标和所提取的四个 主成分之间有着较强的关联性, 主成分可以有效的 提取出信息。

\subsection{4 计算成份得分系数}

得出主成分与各指标的关系。确保主成分可以提 取出指标大部分的信息量之后, 接着分析其与主成 分对应关系情况, 得出组成四个主成分的指标的成 份得分系数表格 8 。

表 8 成份得分系数矩阵

\begin{tabular}{ccccc}
\hline 名称 & \multicolumn{3}{c}{ 成分得分 } \\
\cline { 2 - 5 } & 成分 1 & 成分 2 & 成分 3 & 成分 4 \\
\hline 市场占有率 & 0.112 & -0.067 & 0.374 & 0.663 \\
\hline $\begin{array}{c}\text { 技术性无形资产 } \\
\text { 占比 }\end{array}$ & -0.091 & 0.062 & 0.664 & 0.016 \\
\hline $\begin{array}{c}\text { 研发人员数量占 } \\
\text { 比 }\end{array}$ & -0.257 & 0.383 & 0.141 & 0.107 \\
\hline $\begin{array}{c}\text { 研发投入占营收 } \\
\text { 比例 }\end{array}$ & -0.318 & 0.354 & 0.048 & 0.041 \\
\hline 主营收入增长率 & 0.325 & 0.294 & 0.105 & -0.212 \\
\hline 净利润增长率 & 0.314 & 0.287 & 0.048 & -0.197 \\
\hline 股东权益比率 & -0.226 & 0.195 & -0.333 & -0.034 \\
\hline 资本保值增值率 & 0.063 & 0.107 & -0.366 & 0.647 \\
\hline 可持续增长率 & 0.294 & 0.26 & -0.107 & 0.17 \\
\hline
\end{tabular}

成分得分系数矩阵描述成分和分析项的数学公 式关系, 选择每一主成分表达率最高的指标来表示 该主成分，则根据上表可得:

成分得分 $1=0.325 *$ 主营业务收入增长率 $+0.314 *$ 净利润增长率 $+0.294 *$ 可持续增长率。

成分得分 $2=0.383 *$ 研发人员数量占比 $* 0.354 *$ 研发投入占比。

成分得分 $3=0.664 *$ 技术性无形资产所占比重 $0.333 *$ 股东权益比率。

成分得分 $4=0.663 *$ 市场占有率 $+0.647 *$ 资本保 值增值率。

综上所述, 最终的表达式为: 无形资产指数 $=0.323 *$ 成分得分 $1+0.305 *$ 成分得分 $2+0.197 *$ 成分得分 $3+0.175 *$ 成分得分 4 。

\section{3 微观检验}

\subsection{1 指标的稳定性}

在计算出了无形资产指数之后, 为了验证该指 数在面对每年的不同的上市公司的评估是否保持稳 定, 文本通过计算 12 年到 19 年的指标标准方差来 检验, 计算公式为:

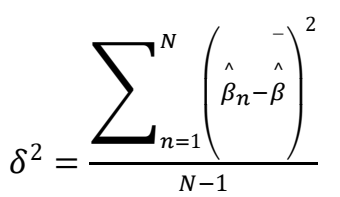

其中, $\mathrm{N}$ 为该年的公司个数, $\hat{\beta}_{n}$ 为第 $\mathrm{n}$ 个公司的 无形资产指数, $\hat{\beta}$ 为所有无形资产指数的均值。

表 9 指数均值表

\begin{tabular}{ccccccccc}
\hline 年份 & 2012 & $\begin{array}{c}201 \\
3\end{array}$ & $\begin{array}{c}201 \\
4\end{array}$ & $\begin{array}{c}201 \\
5\end{array}$ & $\begin{array}{c}201 \\
6\end{array}$ & $\begin{array}{c}201 \\
7\end{array}$ & $\begin{array}{c}201 \\
8\end{array}$ & $\begin{array}{c}201 \\
9\end{array}$ \\
\hline 指数 & 0.06 & 0.1 & 0.2 & 0.3 & 0.3 & 0.3 & 0.6 & 0.5 \\
均值 & 2 & 98 & 81 & 43 & 19 & 02 & 04 & 22
\end{tabular}

得到的结果如表 9 , 从 12 年到 19 年的所有 $\delta^{2}$ 的值均在 1 的左右波动，除去 15 年、 18 年以及 19 年, 其余年份的 $\delta^{2}$ 均小于 0.3 , 表明所计算的无形资 产指数总体较为稳定。

\section{4 宏观检验}

\section{4. 1 拟合优度}

宏观的拟合优度主要衡量在一定的时间序列上, 本文计算得出的无形资产指数能否从总体的角度上, 一定程度上反映创业板上市公司无形资产的变化趋 势。因此本文将创业板上市公司每年的无形资产的 均值以及每年的所有公司的无形资产指数均值作为 纵轴, 以时间为横轴作图, 比较两者的大致发展趋势, 并根据两条折线的趋势线的走势, 得出该指数是否 能在一定程度上反映出整体的变化趋势。该趋势图 如图 6 所示:

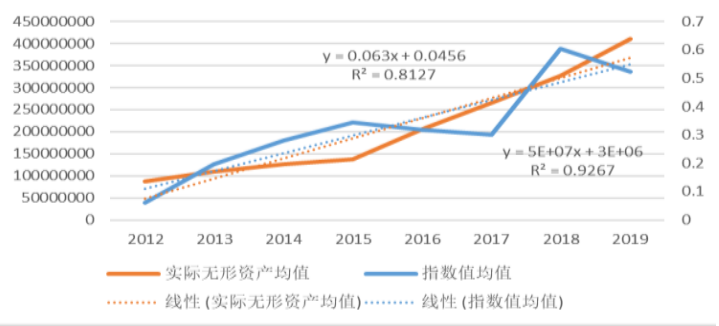

图 6 均值对比图 
(1) 无形资产实际值与指数值均值的模拟趋势 线的相关系数 $R^{2}$ 均大于 0.75 , 表明两条趋势线的拟 合程度、准确性较高。

(2) 两者的趋势线随着时间的变化趋势以及程 度大体相同, 因此该指数的宏观拟合优度较好, 能在 一定程度上反映出创业板上市公司无形资产总体的 变化趋势。

\section{4. 2 模型稳定型}

检验模型的宏观稳定性, 即针对无形资产指数 的年度数据 (即每年的无形资产指数的均值) 计算标 准差, 观察标准差的大小, 来确定该指数在长期是否 具有稳定性。计算公式为:

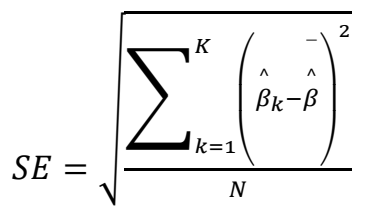

其中 $\mathrm{K}$ 为年份数量, $\beta_{k}$ 为第 $\mathrm{k}$ 年的无形资产指 数均值, $\hat{\beta}$ 为 $\hat{\beta}_{k}$ 的均值。所计算的数据如下表:

结果为: $\mathrm{SE}=0.025613$, 这个数值只占 12 到 19 年指数均值的平均值的 $7.787 \%$, 可见该指数在长期 的时间序列上稳定性较强。

\section{5. 结论与建议}

本文从市场认可度、企业创新能力以及企业可 持续发展能力几个不同维度对创业板上市公司的无 形资产进行了评价, 得出了新的无形资产指数。经过 研究, 本文得出以下几条结论与建议:

（1）首先，每年无形资产价值最大的公司，技 术性无形资产占无形资产的比值都远高于其他公司; 其次, 无形资产市值排名靠前的公司一般资本保值 率都较高。因此企业高管可以考虑通过提高技术型 无形资产的比例，来提升公司的无形资产价值。

(2) 排名上升较快的公司, 例如 C30058 北京 蓝光数据科技公司, 13 年从第 7 上升至 14 年的第一; C300063 广东天龙油墨等公司, 18 年到 19 年上升了 几百名排名, 都有一个共同的特征就是市场占有率 上升很快, 这也表明了无形资产本质上也是公司产 出的一种, 无形资产能够反映和评估创业板公司的 经营绩效，两者之间存在内在的因果联系。

（3）政府部门应当加大对创业板公司的优惠政 策力度, 对那些创新能力较强但出于成长期的公司 增大支持力度, 并巩固加强对知识产权的保护, 建立 健全的企业信息披露制度。

（4）市场投资者在投资创业板这样的创新型公 司时, 除了市场占有率等硬性指标, 还应了解该公司 的研发投入、无形资产的数量以及该公司的技术性
无形资产比率等软件设施, 对自己的决策提供长远 的参考。

\section{6. 不足与展望}

由于受信息来源和数据收集渠道的限制, 本文 仅对创业板的部分公司进行了评价; 并且也并未将 不同的行业细分研究; 考虑每年无形资产价值的时 候并未去除市场上的价格影响; 因此本文还存在许 多不足。但未来以此为基础, 本文还将深入研究无形 资产与企业投入之间的紧密联系，最终真正创新出 一套能够精准动态反映每一家创业板公司的成长状 况的动态评价指标体系。

\section{致谢}

本文受到项目资金资助： 2020 年度中央财经大学大 学生创新创业项目 “构建中国的纳斯达克：基于科 创板评估体系的研究（C2020103578）”、2020 年 度国家民委民族研究项目 “后脱贫时代西部藏区乡 村振兴风险与内置金融研究 (2020-GMB-030)”。

\section{参考文献}

[1] 汤湘希. 论无形资产范围的界定 [J]. 中南财经 大学学报, 1997( 1) : 72-75.

[2] 姜楠. 对无形资产评估价值决定理论的重新认 识 [J]. 东北财经大学学报, 2001（6）：52-55. [3] 骆正清, 陈 艳 辉. 无形资产评估的新方法探 析 [J]. 经济师, 2001（12）：21-22.

[4] 张坤. 无形资产评估的新方法 - 复 合 成 本 法 $[\mathrm{J}]$. 科技进步与对策, 2003（3）： $34-35$.

[5] 周盟农, 黄校徽. 基于实物期权的无形资产价值 评估 ［J］.中国资产评估, 2016（ 1）：42-46.

[6] 谢如松, 李晓伟, 谢肖琳. 无形资产评估中灰色 关联分析法研究 [J]. 财会通讯, 2017（17）：17 -19 .

[7] 裴蓓. 无形资产评估的途径与方法 [J]. 经济视角 (下), 2012 (05) :64-65.

[8] Yuan Zeming, Jin Yu, Wang Tianpei. Research on the Evaluation Index of Intangible Assets of Listed Companies -Based on the Empirical Test of GEM Listed Companies. ACCOUNTING RESEARCH, 2015 (05) : 72$79+95$. 